\title{
WHO LEFT, WHO RETURNED \\ AND WHO WAS STILL AWAY? \\ MIGRATION PATTERNS OF \\ 2003 GRADUATES, 2004-10
}

\author{
Tas Papadopoulos \\ Labour and Immigration Research Centre \\ Labour Group \\ Ministry of Business, Innovation and \\ Employment
}

\begin{abstract}
New Zealand's stock of skills is significantly affected by external migration flows - more so than almost any other developed country. Lack of information, particularly on outward migration, has restricted analysis in the past. However the recent integration of data on border movements into Statistics NZ's Integrated Data Infrastructure (IDI) has opened up new avenues for research. This paper uses this new data to produce descriptive statistics on the extent that graduates from tertiary education institutes leave New Zealand post-completion, and the extent to which they return again. It looks at the cohort of New Zealand students who completed a tertiary qualification in 2003 (the earliest year possible) and looks at migration outcomes up to and including 2010.
\end{abstract}

\section{Introduction}

New Zealand's stock of human capital is significantly affected by migration flows - more so than almost any other developed country. Our emigrants and immigrants make up a relatively large proportion of the New Zealand population, and they both tend to be more skilled than the resident, New Zealand born, population.

Historically, many of those that depart our country have been recent tertiary students. Travelling abroad after study on an Overseas Experience (OE) has long been a part of our culture and recent decades have seen increased migration by young people to Australia.

Understanding this behaviour is important when thinking about what types of tertiary education we should fund and how we should set immigration policy. Thanks to the recent integration of data on international movements across New Zealand's borders into Statistics New Zealand's prototype Integrated Data Infrastructure (IDI), new avenues for migration related research have opened up. This report uses this new data to produce descriptive statistics on the rates at which graduates from tertiary education institutes (TEIs) leave New Zealand post-study, and the extent to which they return again. It looks at the cohort of New Zealand students who completed a tertiary qualification in 2003 and the migration outcomes of this cohort up to, and including 2010.

This new information improves our understanding of the extent that graduates from TEIs are attracted overseas and therefore do not contribute, at least initially, to New Zealand's stock of human capital. It also sheds light on which type of graduate is more likely to leave New Zealand permanently. Over time, as we observe longer-

term migration patterns, this information will also help improve the accuracy of estimates of the returns to government on its investment in tertiary education.

\section{Previous Research}

The OECD has constructed a database on the demographic and labour market characteristics of immigrants living in OECD countries from data primarily sourced from national population censuses. This database shows that in 2006 New Zealand was estimated to have the fifth-highest foreign-born proportion (21 percent) of the resident population in the OECD, and the secondhighest proportion (14 percent) of locally-born people living abroad.

Most of our emigrants are living in Australia. Haig (2010) used Australian census data to look at the characteristics of New Zealanders who have migrated there. It found that New Zealanders working in Australia held similar qualifications to those working in New Zealand and that the mining industry had the highest relative share of New Zealanders in Australia, followed by construction; relative shares of New Zealanders were lower in education and training, public administration, and agriculture, forestry and fishing.

Milne et al (2001) used the longitudinal Dunedin Multidisciplinary Health and Development Study to look at the emigration patterns of young New Zealanders. It found that 26 percent of their sample of people born in Dunedin in 1972/73 moved overseas to live between the 
ages of 18 and 26. The United Kingdom and Australia were the most common destinations.

This study found that "compared to non-emigrants, emigrants had higher IQ scores, were better qualified, leaner and fitter, and had happier and less stress-prone personalities." The authors concluded that most young New Zealanders in their sample who left for overseas were embarking on their OE. "Brain drain emigrants make up a sizeable minority of emigrants, but appear to possess no more skills than those who plan or choose to return."

The Ministry of Education has used earlier integrated administrative datasets to examine the extent that tertiary students go overseas after study. Smart (2006) used the Integrated Dataset on Student Loan Scheme Borrowers (IDS) to examine the likelihood that that students with student loans from the 1997 leaving cohort were declared overseas five years after leaving tertiary study. The key finding was that, after controlling for other factors, a higher student loan leaving balance was associated with a higher likelihood of borrowers being declared overseas.

Smart (2011) used another integrated administrative dataset, the Employment Outcomes of Tertiary Education (EOTE) dataset, to examine the extent that 2003 doctoral graduates were employed in New Zealand post study. The report estimated that around 26 percent of 2003 doctoral graduates were abroad two years after leaving study.

Smyth and Spackman (2012) used similar integrated administrative data to that used in our report. Their dataset was created from linking electronic international movements data for the period from 2007 to 2010, to Inland Revenue data on student loans. They found that about 19 percent of students who left study in 1999 or later, and had student loans, were overseas in 2010. Those who went overseas were more likely to have been aged between 25 and 34 in 2010, studied at higher levels and been successful in their studies.

The prototype IDI database that we used in our research improves on the data that these reports had available. Unlike Smart's research, we can now observe actual graduate migration patterns. And unlike Smyth and Spackman, the IDI allows us to look at emigration outcomes for all participants in tertiary education not just those who have borrowed from the student loan scheme. The IDI also allows us to look at international movements for a wider time period.

\section{Data}

In 2011, Statistics New Zealand began consolidating its linked datasets into the IDI prototype, which also linked in immigration and international movements data supplied by the Department of Labour (Statistics New Zealand, 2012). This report makes use of the new unit record link between tertiary education and international movements data that exists in the IDI prototype. These datasets are linked through the Inland Revenue data which is at the core of the IDI prototype. Records are linked using name, date of birth and sex. Probabilistic linking is used to determine the likelihood that two records from different files belong to the same person.

The linking of international movements to Inland Revenue data in the IDI seems to be of high quality. The international movements data is based on passport information so has high quality demographic information. Initial estimates by Statistics NZ of the proportion of New Zealand citizens in the international movements data who should have been linked to the IDI but weren't (ie the false negative rate) is around 2-5 percent. Statistics NZ estimates that only around 0.3 percent of New Zealand citizens in the international movements data are matched to the wrong person (ie the false positive rate).

The tertiary education data also has high quality linking information. During the time period covered by this report, students were assigned a National Student Number (NSN) which meant that high quality demographic variables were available for probabilistic linking. In addition, around 14 percent of students in the tertiary education data had an IRD number, which allowed for direct matches. For the student population used in this report (see below) the false negative match to IDI appears to be around 4 percent. Statistics NZ estimates the false positive rate to be between 0.8 and 1.5 percent.

The integrated dataset contains information on qualifications (level of qualification and field of study), as well as some information on the student (age, sex, ethnicity, student loan balance). It does not contain information on country of birth, or the number of years the student spent out of New Zealand before 1998, but we can observe whether the student travelled on a non-New Zealand passport between 1998 and 2011. We cannot observe final destination for students that leave New Zealand, but we can observe where the plane disembarked. There are a number of variables that are likely to help explain people's migration decisions, which are missing from the dataset. We discuss these matters more later in this paper.

\section{Population}

The population of interest are New Zealand domestic graduates from tertiary education institutions (TEIs). This excludes international students. It also excludes those in industry training or modern apprenticeships.

The report will look at those New Zealand graduates who completed a qualification in 2003. This is the earliest student population that can be examined in the IDI, as this was the year when the NSN was introduced (the quality of data matching to the IDI is poor before then). Graduates were defined as those who were enrolled in a qualification in 2003, were not enrolled in a qualification in 2004, and their qualification was recorded as completed in either 2003 or 2004.

This report excludes students who left tertiary study in 2003 without completing any qualification. It also excludes a small group of graduates who although domestic students, were observed in the IDI prior to 2003 spending a year or more out of New Zealand using a nonNew Zealand passport. This was done to better define the 
target population of New Zealand domestic tertiary graduates, and remove a group of graduates that may have a strong pre-existing relationship to another country.

\section{Defining extended periods out of New Zealand}

The IDI does not contain data from arrival and departure cards. Instead, this report uses passport and flight data on international movements into and out of New Zealand. Through data integration into IDI, all international movements into and out of New Zealand by each traveller are linked together. This means it is possible to accurately see when someone leaves New Zealand and whether they return.

In some ways this is better than having arrival and departure cards. People's intentions can change after they leave, and what was intended to be a PLT departure doesn't turn out to be or vice versa (ie 'category jumping'). The international movements data records actual behaviour so is not affected by this. Instead of measuring if someone is a PLT migrant, we can identity if someone is out of New Zealand for some extended period.

So how best to define this extended period? Two situations need to be accounted for in any definition. People leave New Zealand for short spells and are still resident in New Zealand. Alternatively, many nonresidents (including New Zealanders that have previously emigrated) visit New Zealand for short periods but do not become New Zealand residents. To account for this, we look at the extent that graduates are in New Zealand or not over annual spells, from 2004 to 2010 , by summing the days spent out of New Zealand each year. 2010 is the latest year of international movements data currently available in the IDI. We then apply a 75 percent (or 275/365 day) threshold for someone moving from 'in NZ' to 'out of NZ'. The Australian Bureau of Statistics (ABS, 2010) applies a similar 75 percent threshold when calculating the impact of net overseas migration on their population estimates.

The rule is implemented as follows. Those in New Zealand in one year, who spend 75 percent or more of the subsequent year out of New Zealand, are defined as being abroad in the subsequent year. Those out of New Zealand in one year, who spend 75 percent or more of the subsequent year back in New Zealand, are defined as being in New Zealand in the subsequent year.

\section{Results}

The diagrams in figure 1, in the appendices at the end of this paper, show how the proportion out of New Zealand each year varies by the level of qualification that the graduate completed in 2003. They show for every age group, the proportion abroad generally increases with qualification level. The differences between levels decrease with age group. For those aged 20 to 24 years who completed higher qualifications, the proportions abroad seem to peak in 2008 to 2009.
The dotted line in the diagrams shows the proportion of all New Zealanders abroad each year. This comparison group is as close as you can get in the IDI to the overall NZ resident population. It captures everybody who received taxable earnings in 2003 - which is about $90 \%$ of adults. New Zealanders as a whole leave at about the same rate as those graduates who completed a level 1-3 certificate. Interestingly, it seems around $18 \%$ of all 20 24 year in 2003 were out of NZ seven years later.

We controlled for the way different characteristics interact using regression modelling. In particular we used logistic regression (as our variables of interest are binomial) and report average marginal effects calculated from the regression coefficients for ease of interpretation

Table 1 at the end of this paper summarises our key results in terms of which 2003 graduates left New Zealand, which returned and which were still away at the end of the study period. These results control for the differences between graduates that we could observe, such as age.

More than a quarter (25.9 percent) of 2003 domestic tertiary graduates left New Zealand between 2004 and 2010 for a year or more. Of those who left in 2004 or 2005, around a quarter (25.6 percent) returned to New Zealand four years later. Of all 2003 graduates, 15.1 percent were abroad in 2010 and had been abroad for at least three years.

\section{Level of qualification}

The likelihood that a 2003 graduate left New Zealand over the following seven years is strongly associated with the level of their qualification. The probability of leaving increases with level, from 18.7 percent for those graduating with a level 1-3 certificate to 48.1 percent of those graduating with a doctorate.

The relationship between qualification level and the likelihood of return after four years was weaker. This may be partly due to data limitations, primarily not being able to observe graduate migration patterns beyond 2010 . From what we could observe, the probability of return was above average for those with level 5-7 diplomas and below average for those with doctorates.

The proportion of 2003 graduates who were abroad in 2010, and had been for at least three years, is strongly related to level, even after controlling for other differences between graduates that we could observe. The proportion of graduates who were abroad, through 2008 to 2010, increases from 10.6 percent for those with level 1-3 certificates to over one third of those with doctorates.

Figure 2 (see appendices) shows that graduates in bachelor and postgraduate qualifications tended to go overseas straight after graduation or after a few years in the workforce. In comparison, graduates in lower level qualifications tended to leave at a more consistent rate over the seven year period. In doing so they are behaving more like the overall New Zealand population. By 2010, the leaving rates across all levels are similar. Like the PLT departure statistics for the overall New Zealand population, there is evidence of leaving rates falling in 
2009 and 2010, around the time of the global financial crisis. However, our fall in leaving rates is magnified by the aging of our cohort of graduates over the seven years. As we have seen, the likelihood of leaving decreases with age.

\section{Field of study}

Table 2 (see appendices) shows that there was not much variation by field of study (after controlling for other differences) in the proportion of 2003 graduates abroad through 2008-10 especially for those with a level 1-3 certificate or a level 4-7 certificate or diploma. There was more variation for those graduates with bachelors or postgraduate qualifications, with graduates in architecture and building being more likely to be abroad through 2008-10, and graduates in agriculture, environmental and related studies being less likely to be abroad. Those with bachelors degrees in education were also less likely to be abroad.

Looking at a more detailed breakdown of qualifications (without controlling for other differences), table 3 (see appendices) shows that there were some qualifications where between a third and 40 percent of 2003 graduates were abroad through 2008-10, many in science, technology, engineering and mathematics (STEM). A number of these specialised qualifications were held by small numbers of graduates, which means that we cannot be confident that future graduates in these qualifications will be abroad at similar rates.

\section{Other characteristics}

There are other characteristics that affect the migration patterns of graduates, even after controlling for other differences. Table 4 (see appendices) shows that the likelihood of being abroad decreases with age, with those aged between 20 and 24 years when completing their qualification being more likely to be abroad seven years later than any other age group. Being female significantly reduced the probability of being abroad through 2008-10, although the effect was relatively small. Asians and those in the 'Other' ethnic group were significantly more likely to be abroad than Europeans. The student loan balance at the time of graduation was positively associated with the likelihood of being abroad, although this effect was relatively small.

We could not identify the final destination for departures from New Zealand, only where their plane had landed. We simplified this information into an 'Australia' or 'rest of the world' variable. Although this is limiting, this variable still had a large association with the probability of returning to New Zealand. Departing graduates whose plane landed in Australia were significantly less likely to return to New Zealand after four years than those whose plane landed elsewhere. We would expect this type of effect given that it is easier for New Zealanders to stay for extended periods in Australia than other countries.

Table 5 (see appendices) shows that around 60 percent of graduate departures landed in Australia, compared to 70 percent of all New Zealand departures aged 17 to 59 years. Across all age groups, with the exception of the 17-20 year olds, graduate departures were less likely to land in Australia than New Zealand departures in general. The likelihood of graduate departures leaving for Australia generally decreases with the level of their qualification, from 79 percent for level 1-3 certificates to 42 percent for doctorates.

\section{Conclusions}

Our results are broadly consistent with what is already known about emigration by New Zealanders. Like official statistics on PLT departures we see that younger people are far more likely to leave than older New Zealanders. PLT statistics show that departures to Australia tend to be lower skilled, based on occupation, than other emigrants, and we find a similar pattern for graduates in terms of qualifications.

Like Smyth and Spackman (2012) and Smart (2006) we find that younger students and those who had studied at higher levels were more likely to be overseas. Like Smart (2006) we find that the student loan leaving balance was positively associated with the likelihood of being abroad, and that borrowers that studied in the fields of agriculture, environmental and related studies and education were less likely to be overseas. Similar to Smart (2011), we find that Asian graduates in postgraduate qualifications, and those with postgraduate qualifications in natural and physical sciences were more likely to be abroad. There is also an overlap in the Australian industries that Haig (2012) found to have lower shares of New Zealanders (education and training, and agriculture, forestry and fishing), and the fields of study whose graduates we found were less likely to leave New Zealand.

There are two key limitations to our analysis. The first is not being able to observe international movements beyond 2010. Because of this, our indicators on those who have left are likely to be more robust than our indicators of return. Second, our analysis is also missing many variables that are likely to help explain people's migration decisions, including comparisons of economic opportunities in New Zealand and abroad, the level of international risk (eg the impact of the global financial crisis), the influence of peers, the pull and push of personal relationships in New Zealand and abroad, and the extent that some graduates can live in countries for extended periods due to where they, or their parents, were born.

Our population of 2003 tertiary graduates could be followed up in five years, to see the extent to which they have returned to New Zealand. The approach used in this paper could also be extended to participants in industry training and modern apprenticeships. It is also possible to look at the extent that international students stay in New Zealand after completing their studies and the extent that their skills replace those of New Zealand tertiary graduates that leave. The proposed integration of arrival and departure card data into the IDI will make it easier to compare the skills that are lost and gained through migration across the entire working age population. 


\section{Notes}

1. The author would like to thank Roger Smyth, Paul Mahoney and Zaneta Park from the Ministry of Education, Robert Didham, Susan Hollows and Kirsten Nissen from Statistics New Zealand and colleague Paul Merwood for their valuable comments on earlier drafts. Special thanks to colleagues Sarah Crichton and Sylvia Dixon for their guidance and detailed comments.

2. This report was undertaken while the author was on secondment to Statistics New Zealand. The results in this report are not official statistics, they have been created for research purposes from the IDI prototype managed by Statistics NZ. On-going work within Statistics NZ to develop the IDI means it will not be possible to exactly reproduce the data presented here. Access to the data used in this study was provided by Statistics NZ in accordance with security and confidentiality provisions of the Statistics Act 1975. Only people authorised by the Statistics Act 1975 are allowed to see data about a particular person, business or organisation. The results in this report have been confidentialised to protect individual people and businesses from identification. Careful consideration has been given to the privacy, security and confidentiality issues associated with using administrative data in the IDI prototype. Further detail can be found in the privacy impact assessment for the Integrated Data Infrastructure available from www.stats.govt.nz. The results are based in part on tax data supplied by Inland Revenue to Statistics NZ under the Tax Administration Act 1994. This tax data must be used only for statistical purposes, and no individual information may be published or disclosed in any other form, or provided to Inland Revenue for administrative or regulatory purposes. Any person who has had access to the unit-record data has certified that they have been shown, have read, and have understood section 81 of the Tax Administration Act 1994, which relates to secrecy. Any discussion of data limitations or weaknesses is in the context of using the IDI prototype for statistical purposes, and is not related to the data's ability to support Inland Revenue's core operational requirements.

\section{References}

Australian Bureau of Statistics. (2010). Migration, Australia, 2008-09 technical note: '12/16 month rule' methodology for calculating net overseas migration from September quarter 2006 onwards. Canberra: Australian Bureau of Statistics.

Haig, R. (2010). Working across the ditch - New Zealanders working in Australia, Wellington: Department of Labour.

Hamer, P. (2007). Māori in Australia: Ngā Māori i te Ao Moemoeā, Wellington: Te Puni Kōkiri.

Milne, BJ, Poulton, R, Caspi A and Moffitt, TE. (2001). Brain drain or OE? Characteristics of young New Zealanders who leave. New Zealand Medical Journal. 1141, 450-3. New Zealand Medical Association.

Scott, D. (2009). What do students earn after their tertiary education? Wellington: Statistics New Zealand.

Smart, W. (2006). Do student loans drive people overseas - what is the evidence? Wellington: Ministry of Education.

Smart, W. (2011). Post doc - do people with doctoral degrees get jobs in New Zealand post study? Wellington: Ministry of Education.

Smyth, R and Spackman, D. (2012). Going abroad What do we know about people going overseas after tertiary study? Wellington: Ministry of Education.

Statistics New Zealand. (2009). Prototype statistics on employment outcomes of tertiary education. Wellington: Statistics New Zealand.

Statistics New Zealand. (2012). Integrated Data Infrastructure and prototype. Wellington: Statistics New Zealand. 


\section{Appendices}

Table 1: Summary of main results, by level of qualification

\begin{tabular}{|c|c|c|c|c|}
\hline Level of study & $\begin{array}{c}\text { Number of } \\
\text { graduates }\end{array}$ & $\begin{array}{c}\text { Of all } 2003 \\
\text { graduates, } \\
\% \text { who left NZ } \\
2004-10\end{array}$ & $\begin{array}{c}\text { Of } 2003 \\
\text { graduates w ho } \\
\text { left in } 2004-05, \\
\% \text { back in NZ in } \\
\text { years } 4 \text { and } 5\end{array}$ & $\begin{array}{l}\text { Of all } 2003 \\
\text { graduates, } \\
\% \text { abroad } \\
2008-10\end{array}$ \\
\hline Level $1-3$ certificates & 14,010 & 18.7 & 23.6 & 10.6 \\
\hline Level 4 certificates & 5,316 & 22.0 & 24.3 & 12.6 \\
\hline Level 5- 7 diplomas & 4,755 & 23.4 & 31.8 & 12.5 \\
\hline Level 7 bachelors/grad & 11,673 & 30.7 & 26.5 & 17.6 \\
\hline Level 8 honours/postgrad & 3,048 & 35.3 & 22.7 & 21.9 \\
\hline Level 9 masters & 1,467 & 34.3 & 22.3 & 21.3 \\
\hline Level 10 doctorate & 354 & 48.1 & 16.7 & 34.9 \\
\hline All levels & 40,623 & 25.9 & 25.6 & 15.1 \\
\hline
\end{tabular}

Source: Figures have been extracted from the IDI prototype managed by Statistics NZ. They have been adjusted to take account of differences between graduates in terms of age, young completer status, sex, ethnicity, leaving student loan amount. Return rates were also adjusted for whether the plane disembarked in Australia or not.

Table 2: The proportion of 2003 graduates abroad through 2008-10, by field of study

\begin{tabular}{|c|c|c|c|c|}
\hline Field of study & $\begin{array}{c}\text { Of all } 2003 \\
\text { graduates, } \\
\% \text { abroad } \\
2008-10 \\
\text { Level } 1-3\end{array}$ & $\begin{array}{l}\text { Of all } 2003 \\
\text { graduates, } \\
\% \text { abroad } \\
2008-10 \\
\text { Level } 4-7\end{array}$ & $\begin{array}{c}\text { Of all } 2003 \\
\text { graduates, } \\
\text { \% abroad } \\
2008-10 \\
\text { Bachelors/grad }\end{array}$ & $\begin{array}{c}\text { Of all } 2003 \\
\text { graduates, } \\
\% \text { abroad } \\
2008-10 \\
\text { Postgraduate }\end{array}$ \\
\hline 01 Natural and Physical Sciences & 14.5 & 9.2 & 23.9 & 30.1 \\
\hline 02 Information Technology & 8.4 & 10.5 & 23.0 & 27.2 \\
\hline 03 Engineering \& Related Techs & 7.3 & 13.2 & 20.6 & 25.1 \\
\hline 04 Architecture and Building & 8.0 & 10.1 & 28.0 & 33.1 \\
\hline 05 Agriculture, Env. \& Related & 5.9 & 8.7 & 16.1 & 10.5 \\
\hline 06 Health & 4.7 & 9.0 & 23.9 & 19.8 \\
\hline 07 Education & 10.3 & 8.7 & 15.1 & 22.6 \\
\hline 08 Management and Commerce & 9.3 & 11.9 & 25.4 & 24.9 \\
\hline 09 Society and Culture & 9.1 & 12.2 & 25.1 & 25.9 \\
\hline 10 Creative Arts & 11.7 & 11.2 & 22.6 & 21.7 \\
\hline 11 Food, Hospitality \& Personal & 10.2 & 11.4 & $\ldots$ & $\ldots$ \\
\hline 12 Mixed Field Programmes & 8.3 & $\ldots$ & $\ldots$ & $\ldots$ \\
\hline All fields & 8.2 & 11.2 & 22.7 & 25.1 \\
\hline
\end{tabular}

Source: Figures have been extracted from the IDI prototype managed by Statistics NZ. They have been adjusted to take account of differences between graduates in terms of age, young completer status, sex, ethnicity, leaving student loan amount. 
Table 3: Proportion abroad 2008-2010 by narrow field of study for level 7 bachelors and graduate qualifications, and postgraduate qualifications

\begin{tabular}{|c|c|c|c|c|c|c|c|c|}
\hline \multirow[b]{2}{*}{ Narrow field of study } & \multicolumn{4}{|c|}{ Bachelors/grad } & \multicolumn{4}{|c|}{ Postgraduate } \\
\hline & Count & $\begin{array}{c}\% \\
\text { Abroad } \\
2008-10\end{array}$ & $\begin{array}{l}\text { Standard } \\
\text { Error }\end{array}$ & $\begin{array}{c}\% \\
\text { Abroad } \\
2008-10 \\
\text { (adjusted) }\end{array}$ & Count & $\begin{array}{c}\% \\
\text { Abroad } \\
2008-10\end{array}$ & $\begin{array}{c}\text { Standard } \\
\text { Error }\end{array}$ & $\begin{array}{c}\% \\
\text { Abroad } \\
2008-10 \\
\text { (adjusted) }\end{array}$ \\
\hline 0101 Mathematical Sciences & 126 & 36.5 & 4.3 & 29.4 & 54 & 37.0 & 6.7 & 28.1 \\
\hline 0103 Physics \& Astronomy & 33 & $S$ & $S$ & s & 27 & S & $S$ & $S$ \\
\hline 0105 Chemical Sciences & 36 & $S$ & $S$ & S & 39 & $\mathrm{~S}$ & S & $S$ \\
\hline 0107 Earth Sciences & 72 & 30.6 & 5.4 & 26.7 & 90 & 41.1 & 5.2 & 33.6 \\
\hline 0109 Biological Sciences & 189 & 23.8 & 3.1 & 20.9 & 177 & 32.8 & 3.5 & 30.0 \\
\hline 0199 Other Sciences & 129 & 21.7 & 3.6 & 21.5 & 57 & 19.3 & 5.4 & 16.0 \\
\hline 0201 Computer Science & 246 & 35.8 & 3.1 & 28.5 & 66 & 42.4 & 6.0 & 26.6 \\
\hline 0203 Information Systems & 504 & 23.6 & 1.9 & 20.2 & 96 & 28.1 & 4.6 & 26.8 \\
\hline 0299 Other Information Technology & 30 & $S$ & $S$ & s & 3 & $S$ & $S$ & $S$ \\
\hline 0307 Mechanical \& Industrial Eng. & 24 & S & S & s & 105 & 39.0 & 4.8 & 27.1 \\
\hline 0309 Civil Engineering & 15 & $S$ & $\mathrm{~S}$ & S & 117 & 38.5 & 4.6 & 27.3 \\
\hline 0313 Electrical \& Electronic Eng. & 75 & 21.3 & 4.7 & 14.8 & 168 & 40.5 & 3.8 & 24.1 \\
\hline 0399 Other Engineering ${ }^{\wedge}$ & 114 & 28.1 & 4.2 & 24.9 & 186 & 33.3 & 3.5 & 23.9 \\
\hline 04 Architecture \& building^ & 264 & 33.7 & 2.9 & 28.1 & 63 & 36.5 & 6.1 & 32.9 \\
\hline 0509 Environmental Studies & 27 & $\mathrm{~S}$ & $S$ & $\mathrm{~S}$ & 33 & S & $S$ & $S$ \\
\hline 0599 Other Agriculture \& Env.^ & 54 & 11.1 & 4.4 & 11.8 & 27 & $S$ & S & $\mathrm{S}$ \\
\hline 0601 Medical Studies & 204 & 25.5 & 3.0 & 17.0 & 180 & 15.6 & 2.7 & 25.0 \\
\hline 0603 Nursing & 1,002 & 16.8 & 1.2 & 23.3 & 219 & 6.8 & 1.7 & 15.8 \\
\hline 0605 Pharmacy & 132 & 40.9 & 4.3 & 28.4 & 18 & $S$ & $S$ & $S$ \\
\hline 0607 Dental Studies & 57 & 40.4 & 6.5 & 28.1 & 21 & S & $\mathrm{S}$ & $S$ \\
\hline 0613 Public Health & 36 & S & $S$ & S & 75 & 13.3 & 3.9 & 21.4 \\
\hline 0617 Rehabilitation Therapies & 249 & 28.5 & 2.9 & 26.4 & 54 & 9.3 & 3.9 & 11.5 \\
\hline 0699 Other Health^ & 228 & 28.9 & 3.0 & 27.2 & 153 & 18.3 & 3.1 & 21.1 \\
\hline 0701 Teacher Education & 2,208 & 10.9 & 0.7 & 14.7 & 90 & 16.7 & 3.9 & 23.8 \\
\hline 0703 Curriculum \& Education Studies & 321 & 10.6 & 1.7 & 17.1 & 147 & 10.9 & 2.6 & 23.9 \\
\hline 0801 Accountancy & 351 & 27.4 & 2.4 & 25.0 & 81 & 25.9 & 4.9 & 21.8 \\
\hline 0803 Business \& Management & 753 & 25.6 & 1.6 & 23.3 & 459 & 19.2 & 1.8 & 26.6 \\
\hline 0805 Sales \& Marketing & 642 & 33.0 & 1.9 & 27.7 & 120 & 21.7 & 3.8 & 21.4 \\
\hline 0811 Banking \& Finance & 204 & 22.5 & 2.9 & 23.4 & 105 & 26.7 & 4.3 & 28.1 \\
\hline 0899 Other Mgmt. \& Commerce^ & 132 & 34.1 & 4.2 & 30.8 & 12 & $S$ & $S$ & $S$ \\
\hline 0901 Political Science \& Policy & 90 & 22.2 & 4.3 & 19.6 & 99 & 19.2 & 3.9 & 18.6 \\
\hline 0903 Studies in Human Society & 369 & 23.6 & 2.2 & 24.2 & 177 & 23.2 & 3.2 & 24.0 \\
\hline 0905 Human Welfare & 186 & 10.2 & 2.2 & 17.4 & 30 & $S$ & $S$ & $\mathrm{~S}$ \\
\hline 0907 Behavioural Science & 276 & 27.2 & 2.7 & 26.4 & 180 & 26.7 & 3.3 & 26.9 \\
\hline 0909 Law & 198 & 26.3 & 3.1 & 23.7 & 732 & 32.5 & 1.7 & 27.8 \\
\hline 0915 Language \& Literature & 402 & 26.9 & 2.2 & 25.7 & 126 & 23.8 & 3.8 & 28.7 \\
\hline 0917 Philosophy \& Religious Studies & 120 & 19.2 & 3.6 & 22.3 & 42 & S & S & S \\
\hline 0919 Economics \& Econometrics & 180 & 40.6 & 3.7 & 33.2 & 117 & 21.4 & 3.8 & 21.2 \\
\hline 0921 Sport \& Recreation & 96 & 24.0 & 4.4 & 23.2 & 27 & $S$ & $S$ & $S$ \\
\hline 0999 Other Society \& Culture ${ }^{\wedge}$ & 141 & 29.8 & 3.9 & 27.4 & 96 & 17.7 & 4.0 & 21.4 \\
\hline 1001 Performing Arts & 159 & 22.6 & 3.3 & 21.1 & 45 & S & S & S \\
\hline 1003 Visual Arts \& Crafts & 291 & 23.4 & 2.5 & 21.8 & 48 & $\mathrm{~S}$ & $\mathrm{~S}$ & $S$ \\
\hline 1005 Graphic \& Design Studies & 372 & 30.9 & 2.4 & 26.2 & 21 & S & S & S \\
\hline 1007 Communication \& Media & 333 & 20.1 & 2.2 & 19.6 & 57 & 22.8 & 5.6 & 25.1 \\
\hline All - fields of study & 11,673 & 22.7 & 0.4 & 22.7 & 4,869 & 25.1 & 0.6 & 25.1 \\
\hline
\end{tabular}

Source: Figures have been extracted from the IDI prototype managed by Statistics NZ.

Note: All counts behind this table have been randomly rounded to base 3 . ' $S$ ' indicates that data has been suppressed for quality or confidentiality reasons. ' $\wedge$ ' indicates that this field aggregates together narrow fields of study that were too small to analyse separately. 
Table 4: The proportion of 2003 graduates abroad through 2008-10, other characteristics

\begin{tabular}{|c|c|c|}
\hline Sex & $\%$ Abroad 2008- 10 & Standard error \\
\hline Male & $16.6 \%$ & $0.3 \%$ \\
\hline Female & $14.0 \%$ & $0.2 \%$ \\
\hline \multicolumn{3}{|l|}{ Age } \\
\hline Under 20 years & $17.1 \%$ & $0.8 \%$ \\
\hline 20- 24 years & $20.5 \%$ & $0.5 \%$ \\
\hline $25-29$ years & $16.0 \%$ & $0.5 \%$ \\
\hline 30- 34 years & $11.7 \%$ & $0.6 \%$ \\
\hline 35- 39 years & $10.1 \%$ & $0.6 \%$ \\
\hline $40-49$ years & $7.3 \%$ & $0.4 \%$ \\
\hline 50 years and over & $5.0 \%$ & $0.4 \%$ \\
\hline \multicolumn{3}{|l|}{ Young completer? } \\
\hline No & $13.7 \%$ & $0.4 \%$ \\
\hline Yes & $16.1 \%$ & $0.4 \%$ \\
\hline \multicolumn{3}{|l|}{ Ethnicity } \\
\hline NZ European & $13.7 \%$ & $0.2 \%$ \\
\hline Māori & $14.4 \%$ & $0.6 \%$ \\
\hline Pacific peoples & $14.7 \%$ & $0.9 \%$ \\
\hline Asian & $24.7 \%$ & $0.8 \%$ \\
\hline Other ethnic groups & $24.4 \%$ & $1.3 \%$ \\
\hline European-Māori & $13.3 \%$ & $0.7 \%$ \\
\hline European-Other ethnic groups & $17.0 \%$ & $0.9 \%$ \\
\hline \multicolumn{3}{|l|}{ Student loan leaving balance } \\
\hline Zero balance & $12.9 \%$ & $0.3 \%$ \\
\hline$\$ 0.01-\$ 10,000$ & $15.7 \%$ & $0.4 \%$ \\
\hline$\$ 10,000-\$ 20,000$ & $15.6 \%$ & $0.4 \%$ \\
\hline$\$ 20,000$ and over & $17.5 \%$ & $0.4 \%$ \\
\hline
\end{tabular}

Source: Figures have been extracted from the IDI prototype managed by Statistics NZ. They have been adjusted to take account of differences between graduates in terms of level of qualification, age, young completer status, sex, ethnicity, leaving student loan amount. 
Table 5: Proportion of leavers to Australia; return rates by level, Australia vs. rest of the world

\begin{tabular}{ll|ll}
\hline Level of Study & $\begin{array}{l}\text { \% of leavers that } \\
\text { left for Australia }\end{array}$ & $\begin{array}{l}\text { \% of leavers to } \\
\text { Australia } \\
\text { returned }\end{array}$ & $\begin{array}{l}\text { \% of leavers to rest } \\
\text { of world that } \\
\text { returned }\end{array}$ \\
\hline Level 1-3 certificates & 79 & 21 & 34 \\
Level 4 certificates & 77 & 21 & 43 \\
Level 5-7 diplomas & 62 & 29 & 29 \\
Level 7 bachelors & 51 & 24 & 27 \\
Level 8 honours & 48 & 21 & 19 \\
Level 9 masters & 51 & 22 & 20 \\
Level 10 doctorates & 42 & 22 & 30 \\
\hline All 2003 graduates & 60 & 23 & \\
\hline
\end{tabular}

Source: Figures have been extracted from the IDI prototype managed by Statistics NZ. 
Figure 1: Proportion of 2003 graduates out of New Zealand each year, by age group and level

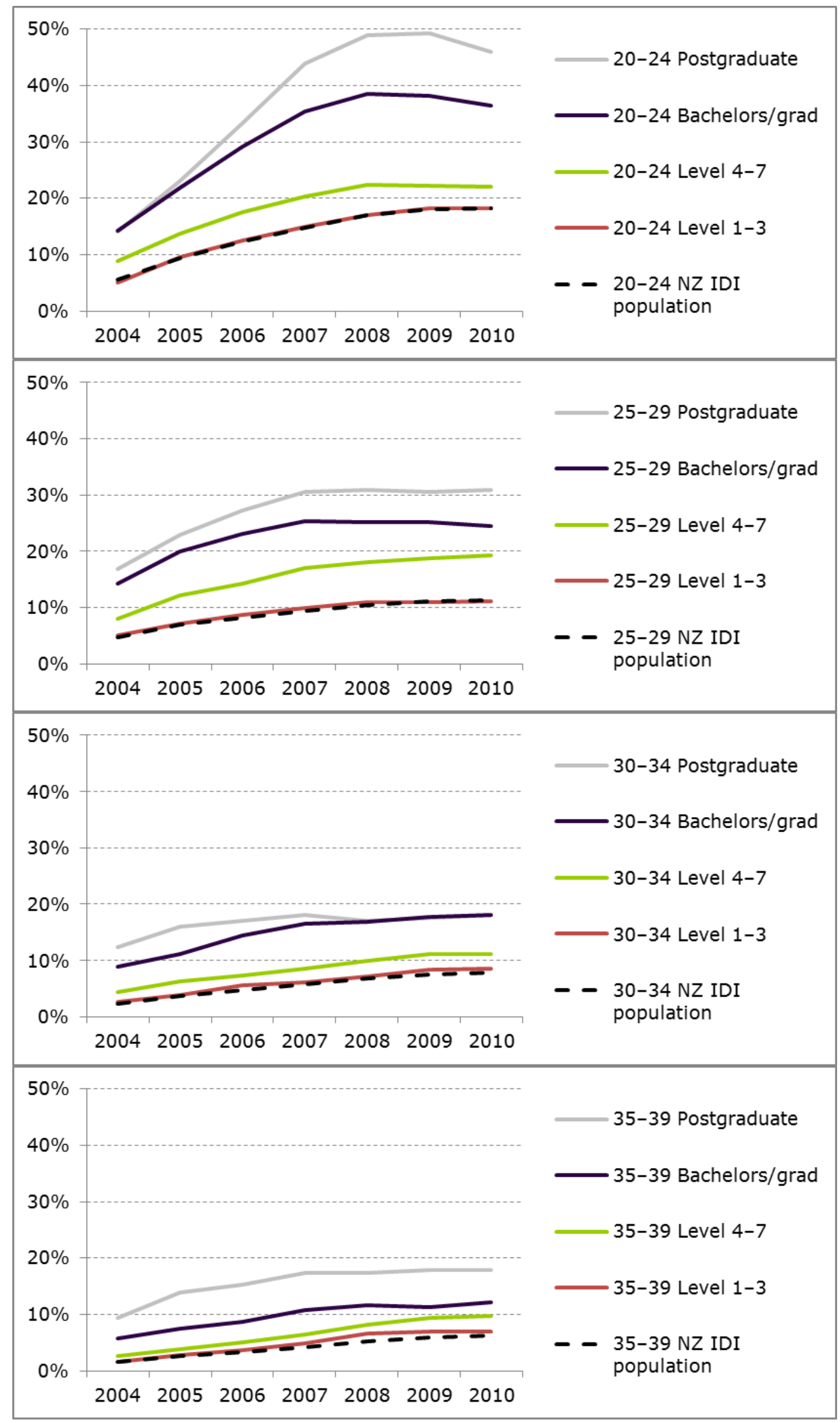


Figure 2: Leaving rates over time for 2003 graduates

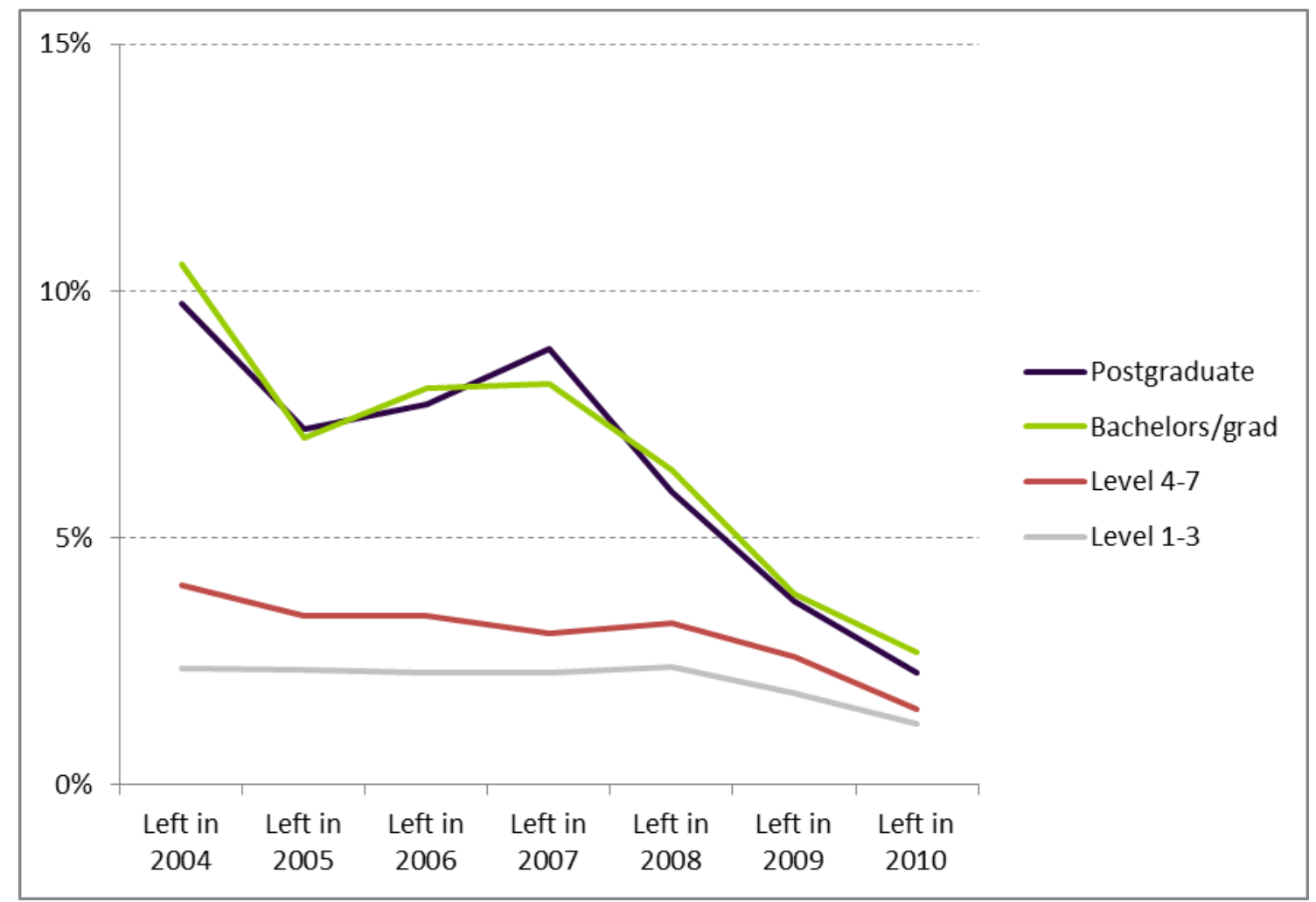

Source: Figures have been extracted from the IDI prototype managed by Statistics NZ. 